\title{
ESC FY2002 Annual Report: Synchrotron-Radiation- Based Photoelectron Spectroscopy at the Advanced Light Source
}

\author{
J. G. Tobin, B. W. Chung, R. K. Schulze, D. K. Shuh
}

October 4, 2002

U.S. Department of Energy

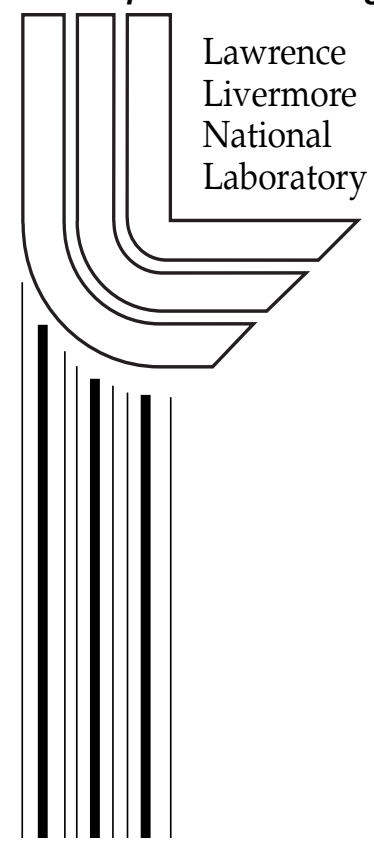




\section{DISCLAIMER}

This document was prepared as an account of work sponsored by an agency of the United States Government. Neither the United States Government nor the University of California nor any of their employees, makes any warranty, express or implied, or assumes any legal liability or responsibility for the accuracy, completeness, or usefulness of any information, apparatus, product, or process disclosed, or represents that its use would not infringe privately owned rights. Reference herein to any specific commercial product, process, or service by trade name, trademark, manufacturer, or otherwise, does not necessarily constitute or imply its endorsement, recommendation, or favoring by the United States Government or the University of California. The views and opinions of authors expressed herein do not necessarily state or reflect those of the United States Government or the University of California, and shall not be used for advertising or product endorsement purposes.

This work was performed under the auspices of the U. S. Department of Energy by the University of California, Lawrence Livermore National Laboratory under Contract No. W-7405-Eng-48.

This report has been reproduced directly from the best available copy.

Available electronically at http://www.doc.gov/bridge

Available for a processing fee to U.S. Department of Energy

And its contractors in paper from

U.S. Department of Energy

Office of Scientific and Technical Information

P.O. Box 62

Oak Ridge, TN 37831-0062

Telephone: (865) 576-8401

Facsimile: (865) 576-5728

E-mail: reports@adonis.osti.gov

Available for the sale to the public from

U.S. Department of Commerce

National Technical Information Service

5285 Port Royal Road

Springfield, VA 22161

Telephone: (800) 553-6847

Facsimile: (703) 605-6900

E-mail: orders@ntis.fedworld.gov

Online ordering: http://www.ntis.gov/ordering.htm

\section{OR}

Lawrence Livermore National Laboratory

Technical Information Department's Digital Library

http://www.llnl.gov/tid/Library.html 


\section{ESC FY2002 Annual Report: Synchrotron-Radiation- Based Photoelectron Spectroscopy at the Advanced Lights Source}

\section{PI: J.G. Tobin}

Collaborators: B.W. Chung, LLNL; R.K. Schulze, LANL; D.K. Shuh, LBNL

\section{Overview}

Despite recent intensive experimental effort [1-3], the electronic structure of $\mathrm{Pu}$, particularly $\delta$-Pu, remains ill defined. An evaluation of our previous synchrotronradiation-based investigation of $\alpha-\mathrm{Pu}$ and $\delta-\mathrm{Pu}$ [1] has lead to a new paradigm for the interpretation of photoemission spectra of $U, N p, \alpha-P u, \delta-P u$ and Am. This approach is founded upon a model in which spin and spin-orbit splittings are included in the picture of the $5 f$ states [4] and upon the observation of chiral/spindependent effects in non-magnetic systems. [5,6] By extending a quantitative model developed for the interpretation of core level spectroscopy in magnetic systems [7], it is possible to predict the contributions of the individual component states within the $5-f$ manifold. This has lead to a remarkable agreement between the results of the model and the previously collected spectra of $\mathrm{U}, \mathrm{Np}, \mathrm{Pu}$ and Am, particularly $\delta-\mathrm{Pu},[1-3,8]$ and to a prediction of what we might expect to see in future spin-resolving experiments. [9] This work was performed under the auspices of the U.S. Department of Energy by the University of California, Lawrence Livermore National Laboratory under Contract No. W-7405-Eng-48. 1.J. Terry, et al, Surface Science Letters 499, L141 (2002).

2.T. Gouder, et al, Europhys. Lett. 55, 705 (2001); MRS Bulletin 26, 684 (2001); Phys. Rev. Lett. 84, 3378 (2000).

3.A.J. Arko, et al, , Phys. Rev. B 62, 1773 (2000).

4.S.Y. Savrosov and G. Kotliar, Phys. Rev. Lett. 84, 3670 (2000).

5.Ch. Roth et al, Phys. Rev. Lett. 73, 1963 (1994).

6.K. Starke et al, Phys. Rev. B 53, 10544 (1996).

7.J.G. Tobin and F.O. Schumann, Surface Science 478, 211 (2001).

8.J.R. Naegele, "Photoem. of Solids," Landolt-Bornstein III/B,183 (1994).

9.J. Tobin, et al, "Photoelectron Spectroscopy of Plutonium at the Advanced Light Source", UCRL-JC-145703, J. Nucl. Sci. Tech./ Proc. of Actinides 2001, accepted 2002.

\section{Indicators of Quality of Work:Publications}

1. J. Terry, R.K. Schulze, J.D. Farr, T. Zocco, K. Heinzelmann, E. Rotenberg, D.K. Shuh, G. van der Laan, D.A. Arena, and J.G. Tobin, "5f Resonant Photoemission from Plutonium," Surface Science Letters 499, L141 (2002).

2. J.G. Tobin, D.A. Arena, B. Chung, P. Roussel, J. Terry, R. K. Schulze, J. D. Farr, T. Zocco, K. Heinzelman, E. Rotenberg, and D. K. Shuh, "Photoelectron Spectroscopy of Plutonium at the Advanced Light Source ", UCRL-JC- 145703, J. Nucl. Sci. Tech./ Proc. of Actinides 2001, accepted, August 2002.

3. J. Tobin, et al, "Resonant Photoemission in f Electron Systems: Pu \& Gd", UCRL-JC-146496, under preparation.

Indicators of Quality of Work: Invited talks by JG Tobin on this subject. 1. March Meeting of the Amer. Phys. Soc., Indianapolis, IN, March 18-22, 2002

2. Pu Workshop, VNIIEF, Sarova, Russia, June 25-27, 2002.

3. 6th Prague Colloquium on f Electron Structure, Prague, The Czech Republic, July 5-8, 2002. 


\section{ESC FY2002 Annual Report: Synchrotron-Radiation- Based Photoelectron Spectroscopy at the Advanced Lights Source}

Motivation: Experimental benchmarking for Input to Models of Pu Aging Many of the input parameters for Aging Models are not directly measurable. These parameters will need to be calculated or estimated. Thus we need a First Principles-Approach Theory, but it is unclear what terms are important in the Hamiltonian. $(H \Psi=E \Psi)$ Therefore, we need experimental data concerning the $5 \mathrm{f}$ electronic structure, to determine which terms in the Hamiltonian are important. Goal: Correct Fundamental Theory for Pu, including Pu Alloys \& Pu Phases. Tool: Double Polarization Photoelectron Spectroscopy (DPPS), which includes chiral excitation and spin-resolving detection. Underlying question: does the spin polarized description capture the essential physics?

Problem: There is no single, atomistic model for both alpha and delta $\mathrm{Pu}$, nor direct experimental verification.

Alpha-Pu is monoclinic, more dense and supposedly more free-electron-like. Delta-Pu is face-centered cubic, less dense and supposedly a correlated-electron material. There is a $20 \%$ volume change between $\alpha$ and $\delta$. There are no maps of either binding energy of the bands (Ag(111)-PRB 32, 3465(1985))) or Fermi crossings (YBCO-PRB 45,5563 (1992)) versus momentum for either phase. (No single crystals...) It is incorrect to assume that a single photoemission spectrum represents the DOS. Photoemission spectra change with energy and angle and there are matrix element effects... Need a new approach!

New Paradigm: It is possible to have spin sensitivity in non-magnetic samples, using Double Polarization Photoelectron Spectroscopy.

$\mathrm{Cu} 3 p$ with Linear Polarization:

Kisker et al, Phys. Rev. Lett.

W $4 \mathrm{f}$ with Circular Polarization:

73, 1963 (1994).

K. Starke et al, Phys. Rev. B

53, 10544 (1996).

New Paradigm: Digression to Core Level Spectroscopy in Magnetic Systems There are dichroic and spindependent effects due to the internal structure of these photoemission peaks and core levels. To the right: X-ray Magnetic Linear Dichroism of $\mathrm{FeCo} / \mathrm{Cu}(001)$. [ See Phys. Rev. Lett. 79, 5166 (1997) and Surf. Sci. 478, 211 (2001).] The comparison of the $\mathrm{FeCo} / \mathrm{Cu}(001)$ dichroism experiment and theory is also shown here. The match using this simple theory is very good.

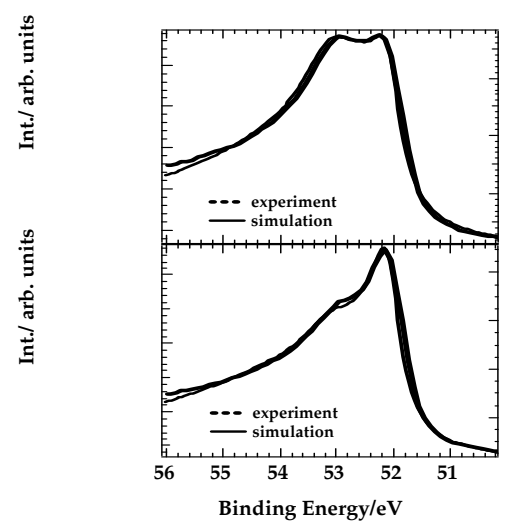

$\mathbf{M} \Uparrow$ 


\section{ESC FY2002 Annual Report: Synchrotron-Radiation- Based Photoelectron Spectroscopy at the Advanced Lights Source}

New Paradigm:The Internal Structure is due to S-O and Exchange splittings. The internal structure of these core levels is due to the interaction of spin-orbit and exchange splitting, complicated by the multi-electronic Doniach-Sunjic lineshape.

Right: (top) The energy positions of the Fe 3p components, split by exchange and spin orbit; (middle) DS lineshapes; (bottom ) the DS asymmetry. Below: The energies of the orthogonalized $3 p$ states, versus exchange (Hs) and spin orbit $(\zeta)$.
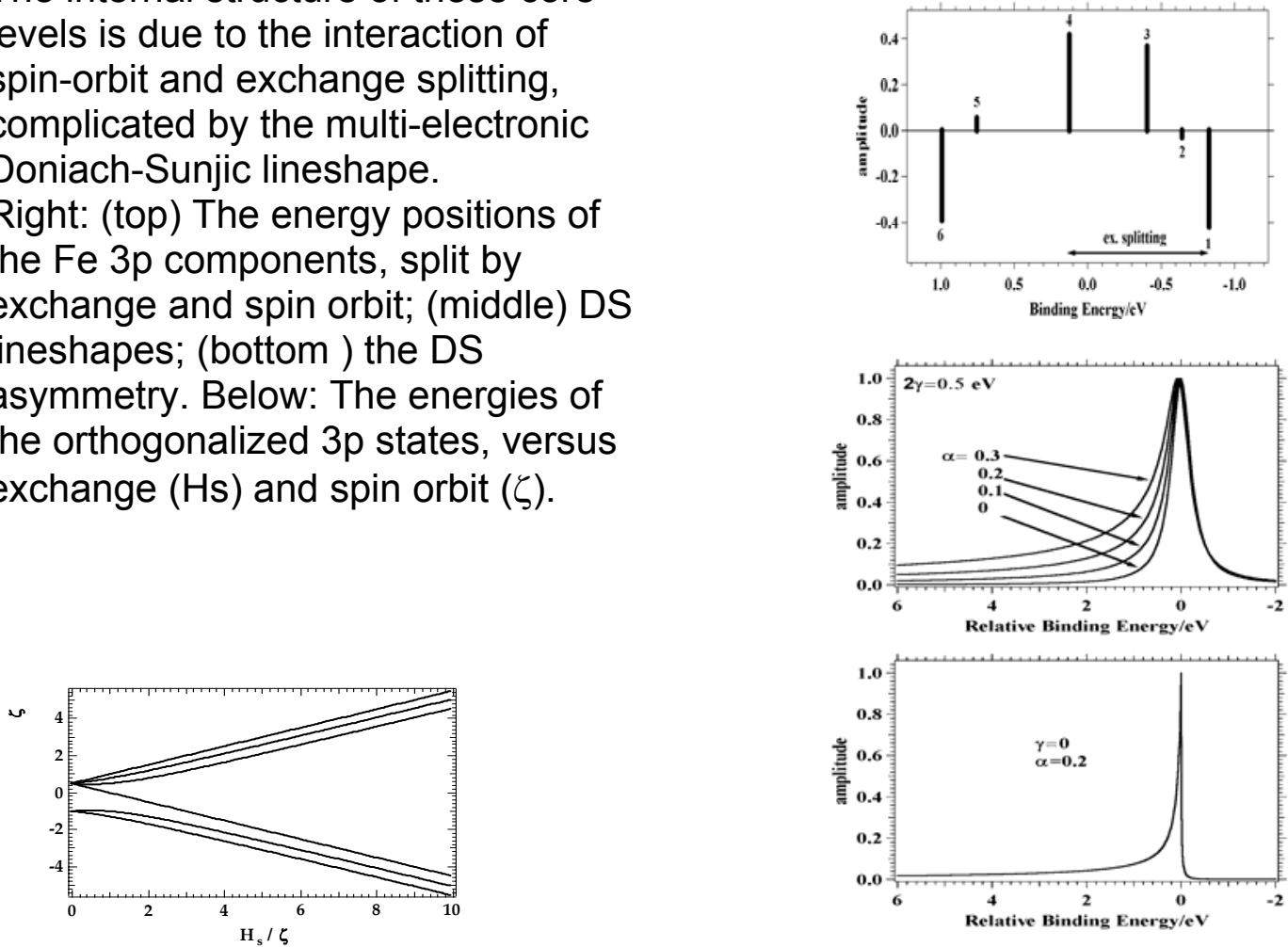

New Paradigm: try to analyze the $\mathbf{5 f}$ valence states with this picture. The recent results of Savrasov and Kotliar et al point in this direction: Phys. Rev. Lett. 84, 3670 (2000). [Also see Soderlind, EuroPhysics Letters 55, 525 (2001).] The salient result is metallization with the retention of "flat-bands, i.e., atomiclike $5 f$ states. These $5 f$ states are spin and orbital momentum specific, just like the components in the $\mathrm{Fe} 3 \mathrm{p}$ manifold. Here, the spin and orbital moments tend to cancel each other, giving a nominally non-magnetic $\delta$ Pu. Cancellation of spin and orbital magnetism in actinides has been observed experimentally, e.g. Lander et al PRB 39, 4719 (1989). 


\section{ESC FY2002 Annual Report: Synchrotron-Radiation- Based Photoelectron Spectroscopy at the Advanced Lights Source}

\section{Comparison of experiment and theory for $\delta-\mathrm{Pu}(\mathrm{n}=5.1)$}

Our experimental result is shown at the right-top. Here, the spectra were taken at a photon energy of $125 \mathrm{eV}$. Spectra for two samples are shown: $\delta$-Pu and $\delta / \alpha-\mathrm{Pu}$, which is bulk $\alpha-\mathrm{Pu}$ with a $\delta$-Pu reconstruction on the surface. (This is following Gouder et al, EuroPhysics Letters.) Soderlind, Landa and Sadigh predict that the $\delta$ $\mathrm{Pu}$ is antiferromagnetic at low temperature with a magnetic moment of $1.5 \mu \mathrm{B}$ due to partial cancellation of large spin and orbital moments. At higher temperatures, they predict that $\delta-\mathrm{Pu}$ is a disordered paramagnet. Reymond and Fournier [J. Alloys. Cmpds. 232, 199(1996)] have reported paramagnetic $\mu$-eff in $\mathrm{Ce}$ and $\mathrm{Ga}$ stabilized $\delta$-Pu of $1.7 \mu \mathrm{B}$ and $1.2 \mu \mathrm{B}$, respectively. Using the above as a guide, we have applied our simple model to this problem. As can be seen from the middle panel, there is significant agreement between the intensity predicted by this simple model and our experimental results. To observe dichroic effects, the disordered paramagnetic $\delta$-Pu would require a double-polarization experiment, with both a chiral probe and true spin detection. The relative magnitude of the dichroism will depend upon the specifics of the experiment.

In the bottom panel, we plot the prediction of a Double Polarization Effect in disordered, paramagnetic $\delta-\mathrm{Pu}$
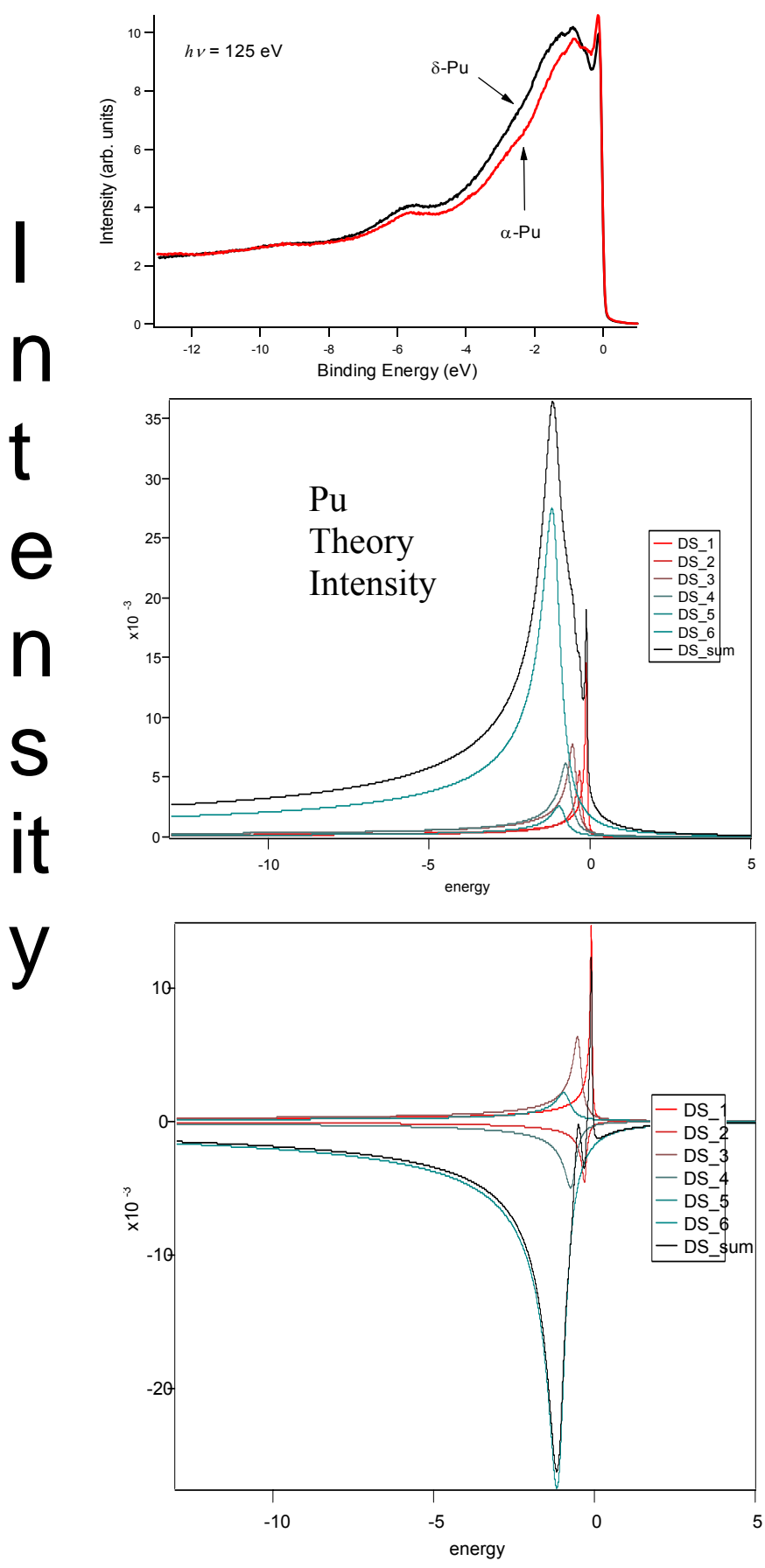
Quantitative agreement of moment cancellation with previous results.

From our model, we can calculate the spin, orbital and total moments versus $\mathrm{Hs} / \zeta$, , assuming the $\mathrm{Pu} 5 f$ electrons are metallic and do not experience angular momentum coupling,i.e., following Savrosov and Kotliar. Soderlind, Landa and Sadigh: $\mu=1.5 \mu \mathrm{B}$. Reymond and Fournier, [J. Alloys. Cmpds. 232, 199(1996)]: $\quad \mu=1.2 \mu \mathrm{B}-1.7 \mu \mathrm{B}$. Savrosov and Kotliar, [Phys. Rev. Lett. 84, 3670 (2000)]: $\mu=1.2 \mu \mathrm{B}$ In the range of $\mathrm{Hs} / \zeta$ near zero, we are in agreement with the above predictions. Our best estimate is $\mathrm{x}$ $=1.6$ which gives $\mu=1.3 \mu \mathrm{B}$.

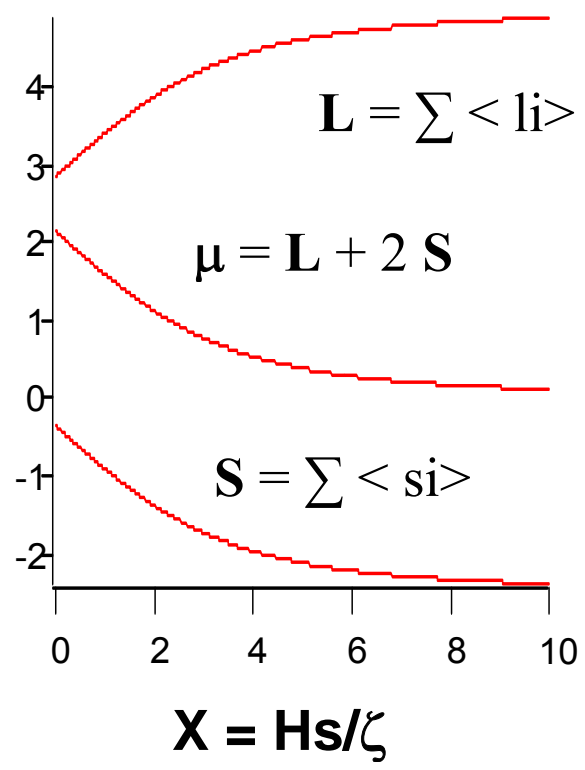

We are building a dedicated, spin-resolving spectrometer for the study of $\mathrm{Pu}$, with sophisticated safety features.

Hepa Filter

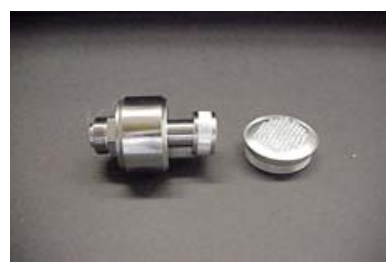

Vacuum Suitcase

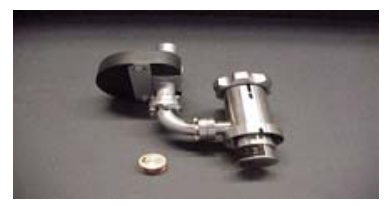

Mini-Mott for spin resolution

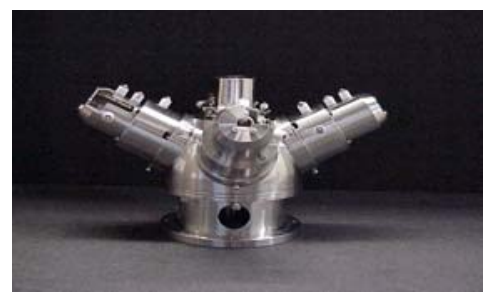

Spectrometer

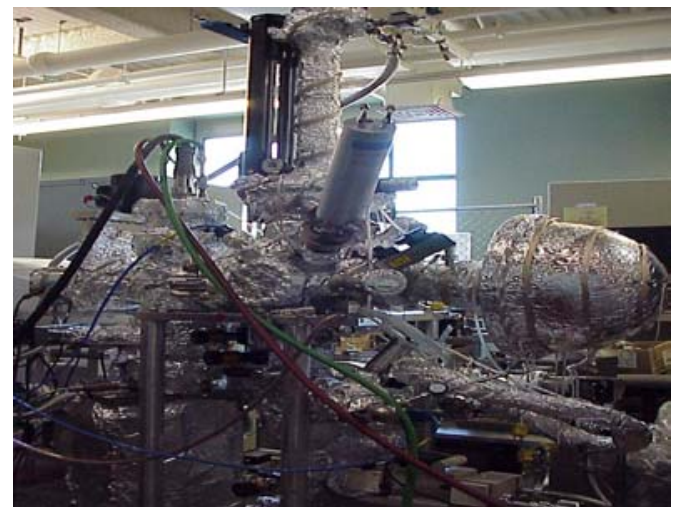

Alpha detectors, not shown, will also be placed throughout the spectrometer. 


\section{ESC FY2002 Annual Report: Synchrotron-Radiation- Based Photoelectron Spectroscopy at the Advanced Lights Source}

LLNL ESC Annual Report-FY02

ESC Task:

LL-61

ESC Task Title: Advanced Characterization-PEEM (Photoelectron Emission Spectroscopy)

MTE Supported: MTE/Project: Pits/Lifetime Task LL-01

Type of Task: Diagnostic

PI: $\quad$ Bill Wolfer/ Jim Tobin

Contributors: B.CHUNG1, R. K.SCHULZE2, and D. K. SHUH3, 1.Lawrence Livermore National Laboratory, Livermore CA

2.Los Alamos National Laboratory, Los Alamos NM

3.Lawrence Berkeley National Laboratory, Berkeley, CA

Deliverable to ESC:

The nature of the electronic structure of alpha and delta $\mathrm{Pu}$

ESC Funding Levels

FY01:

$\$ 365 \mathrm{~K}$

FY02: $\quad$ \$274K

Leveraged Funding

JG Tobin BES FY02: $\quad \$ 370 \mathrm{~K}$

ESC contributions are strongly leveraged with funds from BES (JG Tobin), LBNL, LANL and the Karlsruhe Facility.

People

LLNL: $\quad$ J. Tobin, B. Chung

LBNL: $\quad$ D. Shuh and Safety Personnel

LANL: $\quad$ R. Schulze, et al

Karlsruhe: T. Gouder

Pu Spectrometer

LLNL: Vacuum and Sample Transfer, Spin-Resolution

LBNL: Safety and Pu Sample Handling, Photoelectron Analyzer (\$120K), Ar+

Source ( $\$ 50 \mathrm{~K})$, in house support labs

LANL: Pu Samples and laboratory $x$-ray source $(\$ 60 \mathrm{~K})$, Pre-cleaning facility in Bldg 70A

Karlsruhe: Vapor deposition of $\mathrm{U}$ and $\mathrm{Pu}$ 